\title{
EVALUATION OF Pongamia pinnata SEED EXTRACTS AS AN INSECTICIDE AGAINST AMERICAN BOLLWORM Helicoverpa armigera (HUBNER)
}

\author{
REENA ${ }^{1}$, RAM SINGH² AND SINHA B.K. ${ }^{3}$
}

1Dryland Research Sub-Station, SKUAST-J, Dhiansar, Bari Brahmana- 183311, Jammu, J\&K, India. 2Department of Entomology, CCS Haryana Agricultural University, Hisar- 125 004, India

3Division of Biochemistry and Plant Physiology, FOA, SKUAST-J, Chhatha- 180009, India

*Corresponding Author: Email-sinha_bk@indiatimes.com

Received: June 12, 2012; Accepted: July 10, 2012

\begin{abstract}
Background- Karanj has been reported to possess insecticidal properties; however most of the work done so far is restricted to its oil. Karanj seeds (both mature as well as immature) methanolic extracts (2.5, 5.0, 7.5 and 10.0\%) were assessed for their insecticidal activities against Helicoverpa armigera (Hubner).

Results- The mature seed extract 5.0\% exhibited more than 50\% first instar larval mortality and more than $65 \%$ third instar larval feeding deterrence. Besides, a pronounced decrease in food consumption and utilization indices was noticed when fourth instar larvae were fed on extract treated chickpea pods. Adults when fed on the extract treated sucrose diet (0.5, 1.0, 1.5 and 2.0\%) exhibited a marked reduction in oviposition and egg hatching. Extracts also deterred the adult females from egg laying when applied on to the oviposition substrate (nochoice, choice and without actual contact condition) at concentrations as low as $2.5 \%$. Hatching inhibition of one-day old eggs on application of extracts was recorded. Mature seed extracts gave better results than the immature one, though both were effective.

Conclusion- Repeated application of mature karanj seed methanolic extract $2.5 \%$ may be incorporated in integrated pest management programmes to take care of $H$. armigera menace on crop plants.
\end{abstract}

Key words- Helicoverpa armigera, food utilization indices, methanolic extracts, oviposition deterrence, Pongamia pinnata

Short Title- Karanj seed extracts against $H$. armigera

Citation: Reena, Ram Singh and Sinha B.K. (2012) Evaluation of Pongamia pinnata seed extracts as an insecticide against American bollworm Helicoverpa armigera (Hubner). International Journal of Agriculture Sciences, ISSN: 0975-3710 \& E-ISSN: 0975-9107, Volume 4, Issue 6, pp-257-261.

Copyright: Copyright@2012 Reena, Ram Singh and Sinha B.K. This is an open-access article distributed under the terms of the Creative Commons Attribution License, which permits unrestricted use, distribution and reproduction in any medium, provided the original author and source are credited.

\section{Introduction}

Plants are the richest source of organic chemicals. Many secondary plant metabolites are found to possess insecticidal properties. Plant products and their derivatives sometimes provide effective control of insect pests that have become resistant to other insecticides, are short- lived in the environment, pose relatively low risk to non-target and beneficial organisms and are naturally occurring or can be derived or manufactured with minimal technology and thus cost effective. Besides neem, the work on other botanical pesticides needs to be strengthened considerably [1]. Pongamia pinnata (L.) (Leguminosae and subfamily Papilionacae), common- ly called Indian beach in English and popularly known as karanj, is a hardy, draught resistant, salinity tolerant, medium sized fast growing tree found in almost all parts of India as an avenue tree. Its different parts (viz., leaves, root, bark, flowers and seeds) containing a number of furano-flavonoid compounds are known to possess pesticidal activity. The prinicipal furano flavonoids present in the seed oil are karanjin, pongamol, pongapin, glabrin, karanja chromene, karanjone and pongaglabrone [2]. The insecticidal potential of karanj has been aptly reviewed [3]. Most of the work done so far on karanj is restricted to its oil. 
American bollworm, Helicoverpa armigera (Hubner) is cosmopolitan and is recognized worldwide as an international pest because of its polyphagous and multigenerational nature as well as high damage potential infesting more than 182 species of plants. A survey of insecticide use pattern to control this pest on cotton shows an increasing tendency of the farmers to undertake repeated applications of the insecticides with doses much higher than recommended. About $40 \%$ of the cost of cultivation in cotton accounts for chemical pesticides [4]. Hence, resistance development in this pest has been reported from different parts of the world viz., Pakistan [5]; Australia [6]; India [7], etc.

The risks to human health and environmental side effects have forced to look for greener alternatives to chemical pesticides. Food production today must not only ensure food supply, but also human health and environmental safety, ecological viability as well as cost effectiveness [8]. Hence, in view of these considerations, it was considered worthwhile to assess the efficacy of karanj seeds methanol extract against $H$. armigera.

\section{Experimental Methods}

Pongamia pinnata immature pods were collected during $2^{\text {nd }}$ and $3^{\text {rd }}$ week of April while mature pods were collected during $1^{\text {st }}$ week of May, 2002 from the trees grown on the campus, Chaudhary Charan Singh Haryana Agricultural University, Hisar, India. Seeds were separated by breaking the pods and allowed to shade-dry for a month, after which they were crushed into bits.

Methanolic extract of both mature as well as immature crushed seeds were prepared following the standard procedure of refluxing and distillation [9]. The crushed seeds (2.5 $\mathrm{kg}$ at a time) were taken in a round bottom flask (5 litre cap.) and methanol AR grade (2.5 litres) was added to it to immerse the bits. Refluxing was done by fitting the flask with a water condenser and boiling the set using a heating mantle for $6 \mathrm{~h}$. The extract was then filtered out of the flask and was concentrated by distillation process. This procedure of refluxing and distillation was repeated thrice for complete extraction of active ingredients from Karanj seeds. Likewise $20 \mathrm{~kg}$ seeds (10 kg of mature and immature each) were extracted to obtain 1650 and $1450 \mathrm{ml}$ of methanolic extracts respectively. A stock concentration of ten per cent (w/v) was prepared in acetone and further dilutions were made using water to obtain different concentrations viz., 2.5, 5.0 and $7.5 \%$ of methanolic extracts. Karanj oil (1.0\%) was taken as a standard check. Suitable control (without extract) was also maintained for all the experiments.

Helicoverpa larvae were collected from CCS Haryana Agricultural University chickpea fields during February, 2003 and were reared on chickpea twigs bearing leaves, flower as well as pods as per the standard procedure [10]. All the experiments were conducted under laboratory conditions and were replicated thrice.

\section{Estimation of Contact Larval Toxicity and Antifeedant Action}

Contact toxicity was assessed against freshly hatched $(<12 \mathrm{~h}$ old $)$ first instar larvae using dry film technique. $0.5 \mathrm{ml}$ of different concentrations of extracts and karanj oil (1.0\%) prepared in acetone was taken in rimless test tube $(20.0 \times 2.0 \mathrm{~cm})$ and evaporated by rotating the tube manually using flywheel. The larvae were allowed to remain in contact with dry films for four hours and mortality counts were taken thereafter. Moribund larvae were counted as dead.

\section{Antifeedant Action}

Deterrent activity of various extracts was assayed by offering treated and untreated weighed food (chickpea twigs bearing leaves as well as pods) to ten third instar larvae. The amount of unconsumed food was recorded after $24 \mathrm{~h}$ and per cent antifeedancy was calculated [11]. Weight loss in food due to drying / desiccation was adjusted by keeping suitable controls.

\section{Effect on Consumption and Utilization Indices of Larvae}

Chickpea pods dipped for 30 seconds in various concentrations, air-dried and weighed were provided to ten pre-weighed fourth instar larvae. Observations on increase in larval weight, uneaten food and faecal matter were recorded after $48 \mathrm{~h}$ of feeding. Various indices viz., Consumption index (Cl), Growth Rate (GR), Efficiency of Conversion of Ingested Food (ECl), Approximate Digestibility (AD) and Efficiency of Conversion of Digested Food (ECD) were calculated on wet weight basis [12].

\section{Effect of Treated Diet of Adults on Egg Laying and Subse- quent Hatching of Eggs}

Different concentrations of extracts $(0.5,1.0,1.5$ and $2.0 \%)$ were prepared in 15 per cent sucrose solution. Four pairs of one-day old adults were released in a glass jar $(21 \times 15 \mathrm{~cm})$ with its mouth covered with muslin. A cotton swab dipped in different concentrations of extracts was suspended inside the glass jar and clean muslin was provided as oviposition substrate [13]. Number of egg laid in $48 \mathrm{~h}$ and per cent hatching were recorded.

\section{Assessment of Oviposition Deterrence Effects on Adults} Muslin treated with various concentrations of extracts were exposed to four pairs of adults in different situations viz., choice (half of the oviposition substrate was treated), no-choice (whole of the substrate was treated) and without actual contact (jar was partitioned into two halves using a wire mesh and in one half treated muslin was kept while in other half adults were released along with untreated muslin). Number of eggs laid in $48 \mathrm{~h}$ was recorded under different situations [13].

\section{Evaluation of Ovicidal Action}

Muslin laden with one-day old $H$. armigera eggs (appox. 50) was taken from the general culture for this experiment. The eggs were then dipped for 5 seconds in various concentrations of extracts and per cent hatching was recorded to evaluate the ovicidal action.

\section{Statistical Analysis}

The data were subjected to analysis of variance (ANOVA) in a Completely Randomized Design after appropriate transformations. The difference of two means between treatments exceeding Critical Difference (CD) value is significant [14].

\section{Results \\ Contact Larval Toxicity}

Mature and immature seed extracts were on par with each other in the larval contact toxicity studies (Table 1) at all concentrations tested. With the increase in concentration from $5.0 \%$ to $10.0 \%$, resultant mortalities did not differ significantly, though it was highest at $10.0 \%$ (83.33\%). As compared to control, per cent mortality 
was significantly more in all the treatments. Further, the extracts were superior to karanj oil $(36.67 \%)$ at all concentrations except at $2.5 \%$ where they were comparable with the oil. Acetone in itself was non-toxic as evident from per cent mortality (3.33\%).

Table 1- Contact and antifeedant activity of Pongamia pinnata seed methanolic extract against Helicoverpa armigera

\begin{tabular}{|c|c|c|c|}
\hline Extract & Conc. (\%) & Larval mortality $(\%)^{\mathrm{a}} \mathrm{L}$ & Larval feeding deterrence( $\%)^{a}$ \\
\hline \multirow{4}{*}{$\begin{array}{l}\text { Mature seed } \\
\text { methanolic } \\
\text { extract }\end{array}$} & 2.5 & $40.00(39.23)$ & 42.08 (40.44) \\
\hline & 5.0 & $53.33(46.91)$ & $52.73(46.56)$ \\
\hline & 7.5 & 76.67 (61.12) & $65.03(53.75)$ \\
\hline & 10.0 & $83.33(65.91)$ & $73.77(59.19)$ \\
\hline \multirow{4}{*}{$\begin{array}{l}\text { Immature seed } \\
\text { methanolic } \\
\text { extract }\end{array}$} & 2.5 & $36.67(37.27)$ & $31.69(34.26)$ \\
\hline & 5.0 & $53.33(46.91)$ & $46.45(42.96)$ \\
\hline & 7.5 & $73.33(58.91)$ & $60.11(50.83)$ \\
\hline & 10.0 & 76.67 (61.12) & $67.76(55.40)$ \\
\hline Karanj oil & 1.0 & $36.67(37.27)$ & $36.34(37.07)$ \\
\hline Control (Water) & & & $0.00(4.05)$ \\
\hline Control (Acetone) & & $3.33(8.85)$ & $0.57(5.98)$ \\
\hline $\mathrm{SE}(\mathrm{m}) \pm$ & & (2.69) & $(0.65)$ \\
\hline $\mathrm{CD}(\mathrm{P}=0.05)$ & & (7.92) & (1.89) \\
\hline
\end{tabular}

aFigures in parentheses are arc-sine transformed values

\section{Antifeedant Action}

The extracts treated chickpea pods largely deterred $H$. armigera larvae (Table 1). Minimum deterrence (31.69\%) was recorded on food treated with $2.5 \%$ immature seed methanolic extract, while, the maximum $(73.77 \%)$ in mature seed methanolic extract $(10.0 \%)$ treated food, though all were superior over control. Feeding deterrence (\%) showed a positive correlation with the extracts used. Even at $2.5 \%$ concentration mature seed methanolic extract showed $42.08 \%$ larval feeding deterrence. Mature seed extract proved better than the immature one at all concentrations and excluding immature seed extract (2.5\%). Karanj oil (36.34\%) was inferior to all other treatments.

\section{Consumption and Utilization Indices}

Food consumption, utilization, assimilation and growth efficiencies were significantly inhibited (Table 2) when the $H$. armigera larvae were fed on extract treated food, the inhibition being more at higher concentrations. The indices varied from $3.32-3.79 \mathrm{mg} / \mathrm{mg} / \mathrm{day}$ (Cl), 0.12-0.68 mg/mg/day (GR), 12.56-17.87\% (ECl), 41.99$44.31 \%(A D)$ and $59.77-79.01 \%$ (ECD) at mature seed extract $(10.0 \%)$ and immature seed extract $(2.5 \%)$, while in control they were $\mathrm{Cl}$ (3.99), GR (0.72), ECI (17.92), AD (45.18) and ECD (79.39). Karanj oil was the least effective except immature seed extract $(2.5 \%)$. However, all the treatments effectively reduced the various indices as compared to control.

\section{Effect of Treated Adult Diet on Egg Laying and Hatching}

All the treatments greatly inhibited egg output as well as subsequent hatching of eggs in $H$. armigera adults offered with extract treated sucrose diet (Table 3). At concentrations higher than $2 \%$ methanolic seed extract, mortality of adults was noticed. So, the treatment concentrations were reduced accordingly for this experiment. Even at the lowest concentration (0.5\%) of immature seed methanolic extract, egg laying was greatly reduced (76.00) as compared to control (166.00). Both mature as well as immature seed methanolic extract $(1.0,1.5,2.0 \%)$ proved better than karanj oil (61.67 eggs). At higher concentration (2.0\%) egg laying as well as their subsequent hatching was greatly hampered (6.33 eggs with $26.11 \%$ hatching and 13.00 eggs with $36.21 \%$ hatching in mature and immature seed extract respectively).

Table 2- Assessment of Pongamia pinnata seed methanolic extract on consumption and utilization indices of

Helicoverpa armigera

\begin{tabular}{|c|c|c|c|c|c|c|}
\hline Extract & $\begin{array}{l}\text { Conc } \\
(\%)\end{array}$ & $\begin{array}{l}\text { Con- } \\
\text { sumptio } \\
\mathrm{n} \text { index } \\
\text { (CI) }\end{array}$ & $\begin{array}{l}\text { Growth } \\
\text { Rate } \\
\text { (GR) }\end{array}$ & $\begin{array}{l}\text { Efficiency of } \\
\text { Conversion } \\
\text { of Ingested } \\
\text { Food (ECI) }\end{array}$ & $\begin{array}{l}\text { Approximate } \\
\text { Digestibility } \\
\text { (AD) }\end{array}$ & $\begin{array}{l}\text { Efficiency of } \\
\text { Conversion } \\
\text { of Digested } \\
\text { Food (ECD) }\end{array}$ \\
\hline \multirow{4}{*}{$\begin{array}{l}\text { Mature seed } \\
\text { methanolic } \\
\text { extract }\end{array}$} & 2.5 & 3.62 & 0.59 & 16.23 & 43.91 & 73.94 \\
\hline & 5.0 & 3.59 & 0.54 & 15.06 & 42.96 & 69.99 \\
\hline & 7.5 & 3.44 & 0.49 & 14.16 & 42.71 & 67.12 \\
\hline & 10.0 & 3.32 & 0.12 & 12.56 & 41.99 & 59.77 \\
\hline \multirow{4}{*}{$\begin{array}{l}\text { Immature } \\
\text { seed meth- } \\
\text { anolic extract }\end{array}$} & 2.5 & 3.79 & 0.68 & 17.87 & 44.31 & 79.01 \\
\hline & 5.0 & 3.62 & 0.58 & 16.10 & 43.85 & 73.47 \\
\hline & 7.5 & 3.56 & 0.53 & 14.87 & 43.52 & 68.36 \\
\hline & 10.0 & 3.33 & 0.17 & 14.12 & 42.29 & 66.77 \\
\hline \multirow{2}{*}{$\begin{array}{l}\text { Karanj oil } \\
\text { Control } \\
\text { (Water) }\end{array}$} & 1.0 & 3.72 & 0.60 & 16.20 & 44.10 & 73.52 \\
\hline & & 3.99 & 0.72 & 17.92 & 45.18 & 79.39 \\
\hline $\begin{array}{l}\text { Control } \\
\text { (Acetone) }\end{array}$ & & 4.01 & 0.72 & 17.89 & 45.54 & 78.64 \\
\hline $\mathrm{SE}(\mathrm{m}) \pm$ & & 0.04 & 0.01 & 0.29 & 0.34 & 1.67 \\
\hline $\mathrm{CD}(\mathrm{P}=0.05)$ & & 0.11 & 0.03 & 0.88 & 1.00 & 4.92 \\
\hline
\end{tabular}

Table 3- Effect of karanj seeds methanolic extracts treated sucrose diet on egg laying and per cent hatching of Helicoverpa armigera eggs

\begin{tabular}{|llll|}
\hline Extract & \multicolumn{3}{l}{ Conc. (\%) Mean no. of eggs laid in $48 \mathrm{~h}^{\mathrm{a}}$ Hatching $(\%)^{\mathrm{b}}$} \\
Mature seed & 0.5 & $62.33(7.89)$ & $72.43(58.32)$ \\
methanolic extract & 1.0 & $37.00(6.08)$ & $63.84(53.03)$ \\
& 1.5 & $14.33(3.78)$ & $48.35(44.06)$ \\
& 2.0 & $6.33(2.52)$ & $26.11(30.73)$ \\
Immature seed & 0.5 & $76.00(8.72)$ & $75.48(60.32)$ \\
methanolic extract & 1.0 & $51.67(7.19)$ & $64.45(53.39)$ \\
& 1.5 & $26.33(5.13)$ & $55.54(48.18)$ \\
Karanj oil & 2.0 & $13.00(3.61)$ & $36.21(36.99)$ \\
Control (15\% sucrose & 0.2 & $61.67(7.85)$ & $69.21(56.29)$ \\
solution in water) & $166.00(12.88)$ & $86.15(68.15)$ \\
Control (15\% sucrose & & \\
solution in acetone) & $163.67(12.79)$ & $84.93(67.15)$ \\
SE(m) \pm & $(0.19)$ & $(1.06)$ \\
$\mathrm{CD}(\mathrm{P}=0.05)$ & & $(0.55)$ & $(3.10)$ \\
\hline
\end{tabular}

aFigures in parentheses are square-root transformed values

bFigures in parentheses are arc-sine transformed values

\section{Oviposition Deterrent Action}

Under no-choice condition (Table 4) egg laying capacity of $H$. armigera adults was greatly suppressed, being only 12.33 eggs at $10.0 \%$ mature seed methanolic extract. While, the maximum was in $2.5 \%$ immature seed extract (83.67 eggs), which was too low as compared to control (168.33). Excluding $2.5 \%$ mature and immature seed extracts, karanj oil was inferior to all other treatments. Under choice condition (Table 4) number of eggs laid ranged from 16.67-70.33 on treated and 71.00-83.33 on untreated substrate. Maximum reduction over untreated substrate was recorded at highest concentration $(10.0 \%)$ of mature and immature seed extract $(76.39$ and $75.81 \%$ reduction in egg laying on treated sub- 
strate over untreated respectively in mature and immature seed extract) while, the minimum was at the lowest concentration (2.5\%). Except at $2.5 \%$ concentration, both mature as well as immature seed extracts showed greater suppression of oviposition than karanj oil. $H$. armigera adults laid fewer eggs (Table 4 ) in all the treatments under without actual contact condition of egg laying (varying from 87.33-156.67 eggs) than in control (171.00 eggs), though they were not in direct contact with the treated muslin. It followed the same trend as under no-choice condition, but the effect was less pronounced. All the treatments proved better than karanj oil except mature and immature seed extract $(2.5 \%)$.

Table 4- Effect of extracts on mean no. of eggs laid by 4 females in $48 \mathrm{~h}$ under different conditions of egg laying

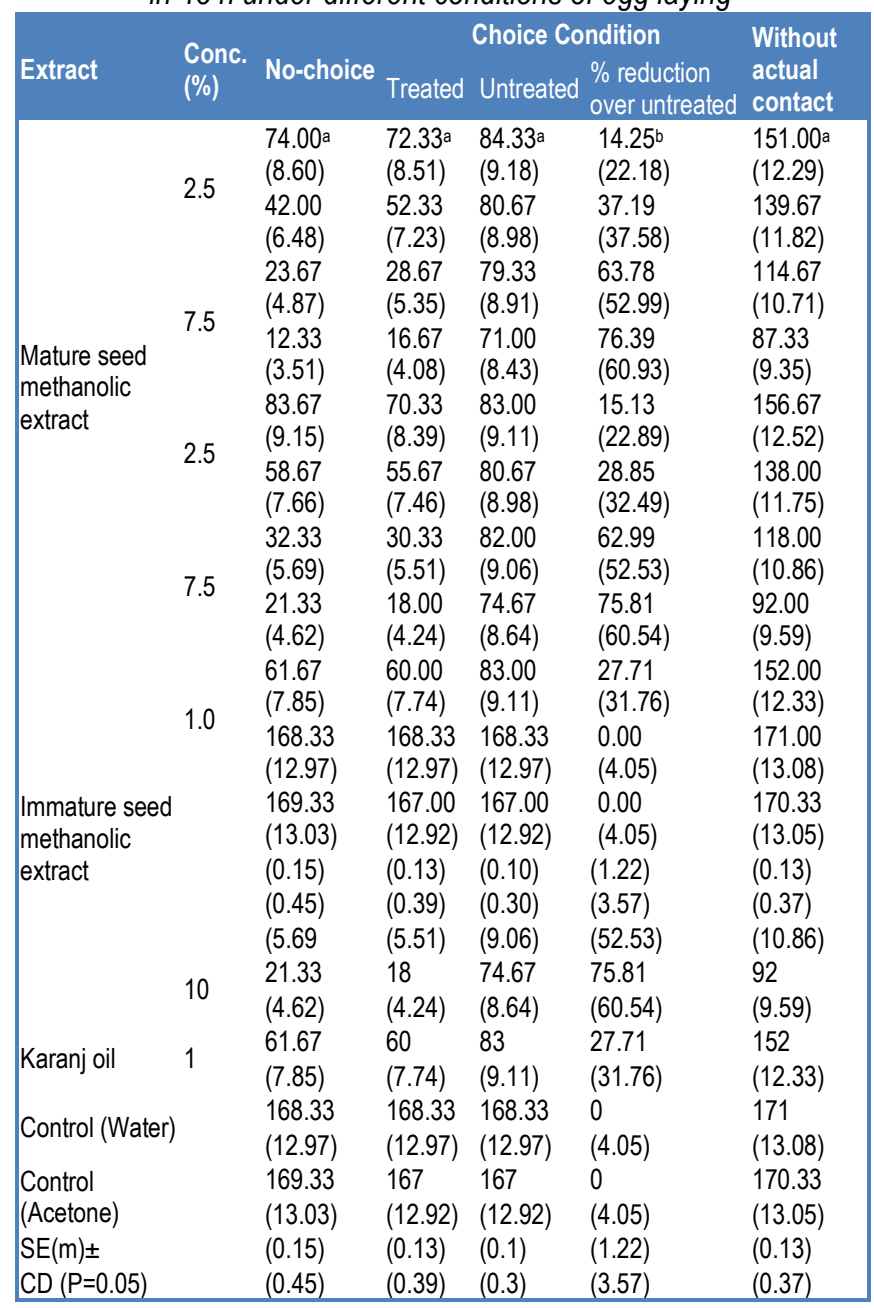

aFigures in parentheses are square-root transformed values bFigures in parentheses are arc-sine transformed values

\section{Ovicidal Action}

The mature seed extracts proved better over the immature one, though both were effective in inhibiting hatching in $\mathrm{H}$. armigera eggs (Table 5) than control. Hatching percentage varied from 22.31-78.13 in mature seed extract (10.0\%) and immature seed extract $(2.5 \%)$ respectively. Significant reduction in hatching was noticed with the progressive increase in concentrations. Methanolic extracts of both mature as well as immature seeds (10.0\%) proved better than karanj oil (1.0\%).

Table 5- Ovicidal action of karanj seed methanolic extracts against one-day old Helicoverpa armigera eggs

\begin{tabular}{|lll|}
\hline Extract & Conc. (\%) & Egg hatching $(\%)^{\mathrm{a}}$ \\
\hline Mature seed & 2.5 & $70.37(57.02)$ \\
methanolic extract & 5 & $51.48(45.85)$ \\
& 7.5 & $38.95(38.62)$ \\
& 10 & $22.31(28.19)$ \\
Immature seed & 5.5 & $78.13(62.12)$ \\
methanolic extract & 7.5 & $57.11(49.09)$ \\
& 10 & $45.03(37.52)$ \\
Karanj oil & 1 & $27.52(31.64)$ \\
Control (Water) & & $36.83(37.37)$ \\
Control (Acetone) & & $91.22(72.76)$ \\
SE(m) \pm & & $84.33(66.68)$ \\
$\mathrm{CD}(\mathrm{P}=0.05)$ & & $(0.48)$ \\
\end{tabular}

\section{Discussion}

The higher efficacy of mature seed extract of methanol compared to that of immature seed (Table 1-5) was probably due to more accumulation of active principles (responsible for insecticidal activity) in the mature karanj seeds.

\section{Contact larval toxicity}

Methanolic extracts exerted mortalities as high as $83.33 \%$ in $H$. armigera first instar larvae. More than $50.00 \%$ larval mortality was noticed at $5.0 \%$ of mature as well as immature seed methanolic extract. Though methanolic seed extract have not been studied so far for its contact action, aqueous karanj plant extract was found toxic to $4^{\text {th }}$ instar Spodoptera litura larvae when applied topically [15].

\section{Antifeedant Action}

Both mature as well as immature seeds methanolic extracts had pronounced antifeedant effect on $H$. armigera third instars; the larval feeding deterrence ranging from $42.08-73.77 \%$ in mature and $31.69-67.76 \%$ in immature seed methanolic extract (Table 1). Study on this aspect of karanj seed extract is lacking. However, antifeedant properties of aqueous karanj extract have been reported against various pests [16].

\section{Consumption and Utilization Indices}

The concentration dependent reduction in dietary utilization indices (Table 2) relative to controls is directly related to the reduction in food consumption. This conclusion is corroborated by the results of direct bioassays for larval feeding deterrence, the treated food no-choice tests (Table 1), where substantial feeding inhibition on treated food was observed. This suggests that reduction in growth may result from both behavioural and physiological (post ingestive) effects [17]. The reduced ECI and ECD result from a reduction in the efficiency to convert foodstuffs into growth, perhaps by a diversion of energy from production of biomass into detoxification [18]. Likewise, rate of food consumption, assimilation and production by $5^{\text {th }}$ instar Euproctis fraterna larvae, showed a negative correlation with the concentration of $P$. pinnata leaves acetone extract [19]. 


\section{Effect of Treated Adult Diet on Egg Laying and Hatching}

$H$. armigera adults fed on extracts treated sucrose diet laid fewer eggs and per cent hatching of eggs was also significantly reduced (Table 3). Decrease in egg laying and hatching was in a concentration dependent manner, the reduction being more at higher concentrations and vice versa. Adult mortality at concentrations higher than $2.0 \%$ shows the toxic effect of these extracts on $\mathrm{H}$. armigera adults. Suppressed fecundity reveals the effect of adult diet on its various physiological activities. Further, reduced hatching (\%) shows the carry over effect of these extracts. Likewise, Helopeltis theivora adults fed with karanj aqueous extract treated shoots exhibited reduced fecundity [20]. The resultant F1 adults obtained from the adults fed with treated shoots and further reared on untreated shoots also exhibited similar effect, but to a lesser extent.

\section{Oviposition Deterrent Action}

Oviposition as well as subsequent egg hatching was greatly hampered (Table 4) under all the three situations of egg laying. Reduced egg laying under no-choice condition shows the capacity of karanj seed methanolic extract to render the host plant unsuitable on application for egg laying by $\mathrm{H}$. armigera. Moreover, given a choice between treated and untreated host plant, the $H$. armigera females will prefer the untreated one as clear from the choice experiment. Reduction in oviposition on the untreated substrate as well as egg hatching under choice and without actual contact conditions could be due to the deterrent / repellent action of the volatiles emanating from the treated substrate. Reduction in egg hatching especially on the treated substrate demonstrates the contact action of the extracts on eggs as proved in our earlier experiment with larvae (Table 1). Though karanj oil has been found to act as oviposition deterrent against several pests [21, 22], but in the present study, oil was found less effective than the extracts.

\section{Ovicidal Action}

The extracts adversely affected hatching in $H$. armigera eggs as evident form Table 5. Reduction in egg hatching demonstrates the contact action of extracts on one-day old $H$. armigera eggs even when exposed for just five seconds. Even at the lowest concentration tested $(2.5 \%)$ the extracts reduced egg hatching to 70.37 and $78.13 \%$ in mature and immature seed methanolic extract, while in control it was $91.22 \%$. Egg hatchability of Corcyra cephalonica was disrupted by the application of aqueous karanj seed extracts [22].

\section{Conclusions}

There are possibilities of incorporating mature karanj seed methanolic extract in integrated pest management programmes at $5.0 \%$ concentration. Repeated application of this extract at different stages of insect development can very well take care of $H$. armigera on crop plants like cotton, etc., where it is a menace. The results demonstrate the potential of karanj seed extracts for further development into a botanical insecticide against $H$. armigera under field conditions considering its effectiveness as well as ease of preparation.

\section{References}

[1] Jayaraj S. (2002a) Modern Trends in Integrated Pest Management., $1-9$.

[2] Bringi N.V. (1987) Non traditional oil seeds and oils in India.

[3] Kumar M. and Singh R. (2002) Biol. Agric. Hort., 20, 29-50.

[4] Jayaraj S. (2002b) Modern Trends in Integrated Pest Management, 188-191.

[5] Ahmad M., Arif M.I. and Ahmad Z. (2003) Crop Prot. 22(3), 539-544.

[6] Gunning R.V. and Moores G.D. (2002) The BCPC Conference Pests and Diseases, 1\&2, 793-798.

[7] Phokela A., Rao R.V.S. and Singh S.P. (2002) Indian J. Ent. 64(1), 108-110.

[8] Paroda R.S. (2003) Sustaining our Food Security.

[9] Kumar R., Ram Singh, Bharti Suhag P. and Kalidhar S.B. (2001) J. Cotton Res. Dev. 15, 156-161.

[10]Jaglan M.S., Khokhar K.S., Malik M.S. and Singh R. (1997) J. Agric. Food Chem. 45, 3262-3268.

[11]Facknath S. and Kawol D. (1993) Insect Sci. Applic., 14, 571574.

[12]Waldbauer G. (1968) Adv. Insect Physiol., 5, 229-288.

[13]Gajmer T., Singh R., Saini R.K. and Kalidhar S.B. (2002) J. App. Ent., 126, 238-243.

[14]Panse V.G. and Sukhatme P.V. (1978) Indian Council of Agricultural Research, New Delhi.

[15]Behera U.K. and Satapathy C.R. (1996) Insect Envi., 2, 43-44.

[16]Rao N.S., Rajendran R. and Raguraman S. (2002) J. Ent. Res. 26, 233-238.

[17]Koul O. and Isman M.B. (1990) J. Insect Physiol. 37, 591-598.

[18]Koul O. and Isman M.B. (1991) Insect Sci. Applic.111, 47-53.

[19]Sridhar S. and Chetty J.S. (1989) Proc. Indian Acad. Sci., Animal Sci., 98, 313-323.

[20]Deka M.K., Handique R., Singh K. and Hazarika L.K. (1998) Crop Res., 16(1), 102-105.

[21]Morale R.S., Sarnaik D.N., Satapute U.S. and Sadawarte A.K. (2000) Pestology, 24(1), 26-28.

[22]Yadav J.P. and Bhargava M.C. (2002) Indian J. Plant Prot. 30 (2), 207-209 